\title{
ANALISIS FAKTOR YANG BERHUBUNGAN DENGAN KOHESIVITAS KELOMPOK TANI DALAM PENGGUNAAN VARIETAS UNGGUL BARU KOMODITAS PADI
}

\author{
Analysis of Related Factors on the Cohesiveness of Farmer Groups in the Use of New \\ Superior Varieties of Rice Commodities
}

\author{
Rachma Luviani, Abdul Farid, Irianti Kurniasari \\ Program Studi Penyuluhan Pertanian Berkelanjutan Polbangtan Malang \\ Email: rluviani04@gmail.com
}

Diterima 16 Juli 2019, disetujui 2 Mei 2020

\begin{abstract}
ABSTRAK
Penurunan kohesivitas kelompok tani menjadi salah satu permasalahan yang dihadapi kelompoktani saat ini.Petani beranggapan bahwa kelompoktani hanya menjadi alat bagi sebagian masyarakat atau kelmpok tertentu untuk mendapatkan bantuan dari pemerintah.Penelitian ini bertujuan untuk : 1) Mendeskripsikan karakteristik petani di Desa Karangrejo Kecamatan Kendal; 2) Mendeskripsikan kohesivitas kelompoktani yang ada di Desa Karangrejo Kecamatan Kendal; 3) Menganalisis hubungan antara karakteristik petani dan kohesivitas kelompoktani dalam penggunaan Varietas Unggul Baru komoditas padi. Metode yang digunakan dalam penelitian ini adalah metode kuantitatif deskriptif dengan analisis korelasi Rank Spearman.Hasil penelitian menunjukan bahwa karakteristik petani di Desa Karangrejo yaitu petani memiliki umur petani rata-rata 42-51 tahun, pendidikan petani rata-rata SMA, pelatihan dalam bidang pertanian yang dilakukan rata-rata 3-4 kali, lama usaha tani berada direntang 11-20 tahun, luas lahan rata-rata 0,2-0,4, tingkat kosmopolitan rendah, interaksi penyuluh tinggi dan pemanfaatan media terhadap kohesivitas kelompok tinggi. Tingkat kohesivitas berada pada kategori tinggi. Hubungan yang signifikan positif terdapat pada tingkat pendidikan, interaksi dengan penyuluh, dan pemanfaatan media, sedangkan untuk pelatihan, lama berusahatani, dan tingkat kosmopolitan memiliki hubungan yang tidak signifikan dan bernilai negatif, kemudian untuk umur dan luas lahan memiliki hubungan yang tidak signifikan dan bernilai positif.

Kata kunci: karakteristik petani, kohesivitas kelompoktani, varietas unggul baru komoditas padi

\section{ABSTRACT}

The decline in farmer group cohesiveness is one of the problems faced now. In addition, farmers assume that the farmer group is only a tool for some communities or certain groups to get assistance from the government. This research aims to: 1) Describe the characteristics of farmers in Karangrejo Village, Kendal District; 2) Describe the group cohesiveness in the Karangrejo Village, Kendal District; 3) Analyzing the relationship between farmer characteristics and farmer group cohesiveness in the use of new rice seed varieties. The method used in the research is descriptive quantitative method with Spearman rank correlation analysis. The results showed that the average age of farmers was 42-51 years, education of average farmers was high school, training was carried out on average 3-4 times, the length of farming was 11-20 years, the average land area was 0.2- 0.4, the cosmopolitan level and the use of media are categorized as high. The level of cohesiveness is in the high category. Relationships that were significantly positive were found in education, interaction with extension agents, and the use of media, while for training, long-term farming, and cosmopolitan had a non-significant and negative relationship, then the age and land area associated were not significant and positive.
\end{abstract}

Keywords: characteristics of farmers, group cohesiveness, superior varieties of rice commodities 


\section{PENDAHULUAN}

Sektor pertanian menjadi salah satu sektor yang sangat penting dalam proses pembangunan di Indonesia. Pemerintah kini memfokuskan pembangunan sektor pertanian pada peningkatan produksi tanaman pangan terutama tanaman padi. Salah satu cara yang dilakukan dalam peningkatan produksi salah satunya dengan menggunakan Varietas Unggul Baru (VUB). Program penggunaan varietas unggul baru komoditas padi ini diterapkan pada kelompok tani yang melakukan budidaya tanaman padi dengan produktivitas rendah. Adanya program tersebut diharapkan petani lebih tertarik untuk melakukan kegiatan dalam kelompok sehingga kelompok tani dapat berfungsi sebagaimana mestinya. Apabila anggota kelompok semakin tertarik untuk tetap berada dalam kelompoknya diharapkan dapat menumbuhkan kohesivitas dalam kelompoktani untuk saling bekerjasama antar anggotanya. Sebuah kelompok tani yang kohesif maka memudahkan tercapainya tujuan kelompok tersebut.

Kohesivitas kelompok merupakan kondisi dimana anggota tim tertarik untuk tetap bersatu, adanya kebersamaan, saling merasakan dan memiliki perasaan anggota lain dengan emosional yang positif (Walgito (2007), Robbins dan Judge (2009), Yuniasanti (2010)). Sebuah kelompoktani dikatakan kohesif apabila masing-masing anggotanya memiliki ikatan yang sangat erat didalam kelompoknya. Kohesif atau tidaknya kelompoktani dapat dilihat dari banyaknya kegiatan dan kerjasama yang dilakukan dalam kelompok tersebut, selain itu dapat dilihat bagaimana kerjasama yang dilakukan antar anggota kelompok.

Kecamatan Kendal merupakan salah satu daerah yang mendapatkan programpenggunaan VUB komoditas padi di Kabupaten Ngawi.Salah satu permasalahan mengenai kelompoktani yang ada di wilayah Kecamatan Kendal adalah adanya penurunan kohesivitas kelompoktani hal ini dapat dilihat dari kurangnya partisipasi anggota dalam melakukan kegiatan kelompok. Penurunan kohesivitas tersebut dikarenaka petani menganggap seolah-olah kelompoktani hanya menjadi alat bagi sebagian masyarakat atau kelompok tertentu untuk mendapatkan bantuan dari pemerintah.

Penelitian ini bertujuan untuk: 1) Mendeskripsikan karakteristik petani di Desa Karangrejo Kecamatan Kendal; 2) Mendeskripsikan kohesivitas kelompoktani yang ada di Desa Karangrejo Kecamatan Kendal; 3) Mengetahui faktor-faktor yang berhubungan dengan kohesivitas kelompoktani dalam penggunaan VUB komoditas padi.

\section{METODE PENELITIAN}

Penelitian ini dimulai bulan Maret sampai Mei 2019 dan dilakukan di Kelompoktani Ngudi Rahayu dan Kelompoktani Sedyo Mulyo, Desa Karangrejo, Kecamatan Kendal. Pemilihan lokasi kajian ini dilakukan secara purposive, dengan pertimbangan desa tersebut mendapatkan program penggunaan VUB komoditas padi. Metode yang digunakan dalam penelitian ini yaitu metode kuantitatif deskriptif. Populasi penelitian yaitu kelompoktani Ngudi Rahayu dengan jumlah 44 orang dan kelompoktani Sedyo Mulyo dengan 1 anggota 40 orang. Sehingga populasi yang diperoleh sebanyak 84 orang. Teknik pengambilan sampel yaitu menggunakan proportionate stratified random sampling dengan menggunakan rumus Slovin. Sehingga sampel yang diperoleh dari 84 populasi yaitu:

$$
\begin{aligned}
& n=\frac{N}{1+N(e)^{2}} \\
& n=\frac{84}{1+\left(84(0,05)^{2}\right)} \\
& n=\frac{84}{1+0,21} \\
& n=\frac{84}{1,21} \\
& n=69,42
\end{aligned}
$$


Dikarenakan kajian dilakukan pada dua kelompoktani yang memiliki anggota atau unsur yang tidak homogen dan berstrata secara proporsional maka untuk menentukan besarnya sampel pada masing-masing kelompok dilakukan dengan alokasi proposional agar sampel yang diambil lebih proporsional yaitu dengan penghitungan dengan rumus sebagai berikut:

Kelompoktani Ngudi Rahayu

$$
\begin{aligned}
\text { Jumlah sampel tiap kelas } & =\frac{\text { Jumlah sampel }}{\text { Jumlah Populasi }} \times \text { Jumlah tiapkelas } \\
& =\frac{70}{84} \times 44 \\
& =37
\end{aligned}
$$

Kelompoktani Sedyo Mulyo

$$
\begin{aligned}
\text { Jumlah sampel tiap kelas } & =\frac{\text { Jumlah sampel }}{\text { Jumlah Populasi }} \times \text { Jumlah tiapkelas } \\
& =\frac{70}{84} \times 40 \\
& =33
\end{aligned}
$$

Sehingga diketahui sampel 37 orang pada kelompoktani Ngudi Rahayu dan 33 orang pada Kelompoktani Sedyo Mulyo.Teknik pengumpulan data yaitu dengan wawancara dan penyebaran kuisioner.Pengukuran variabel dilakukan menggunakan skala Likert.Analisis yang dilakukan yaitu menggunakan rumus interval dan korelasi Rank Spearman.Variabel penelitian dapat dilihat pada Tabel 1.

\section{HASIL DAN PEMBAHASAN}

\section{Deskripsi Karakteristik Petani di Desa Karangrejo}

Karakteristik petani merupakan ciri-ciri a tau sifat-sifat yang dimiliki oleh seorang peta ni yang ditunjukkan melalui pola pikir, pola si kap dan pola tindakan terhadap lingkungan (Mislini, 2006).

Berdasarkan Tabel 2 dapat diketahui

\begin{tabular}{|c|c|c|}
\hline No & Variabel & Subvariabel \\
\hline 1 & $\begin{array}{c}\text { Karakteristik } \\
\text { Petani }\end{array}$ & $\begin{array}{l}\text { Umur } \\
\text { Pendidikan } \\
\text { Pelatihan } \\
\text { Lama Berusahatani } \\
\text { Luas Lahan } \\
\text { Tingkat } \\
\text { Kekosmopolitan } \\
\text { Interaksi dengan } \\
\text { Penyuluh } \\
\text { Pemanfaatan } \\
\text { Media }\end{array}$ \\
\hline 2 & $\begin{array}{l}\text { Kohesivitas } \\
\text { Kelompok }\end{array}$ & $\begin{array}{l}\text { Loyalitas } \\
\text { Solidaritas } \\
\text { Daya Tarik } \\
\text { Kerjasama }\end{array}$ \\
\hline
\end{tabular}
bahwa petani di Desa Karangrejo berusia rata-rata 43-51 tahun atau 37.1\% yang artinya tergolong kategori produktif. Menurut BPS, umur produktif seseorang dalam bekerja
Tabel 1. Variabel Penelitian

berada antara 15-64 tahun. Rata-rata pendidikan petani yaitu SMA dengan jumlah 31 orang atau $44,3 \%$. Luas lahan yang dimiliki petani yaitu $0,2-0,4$ ha, hal ini berarti lahan yang dimiliki responden masih tergolong sempit, hal ini berpengaruh terhadap penggunaan bibit dalam program penggunaan VUB tergolong sempit. Penggunaan benih pada lahan sempit dapat diatasi dengan melakukan persemaian kering, sehingga diharapkan agar tidak terjadi penurunan produktivitas.

Berdasarkan Tabel 3 diketahui pelatihan pertanian yang dilakukan petani yaitu 3-4 kali dengan jumlah 24 orang atau 34,3\%, ini menu njukan bahwa pelatihan khususnya berkaitan dengan usahatani padi yang dilakukan petani intensitasnya masih sedikit. Pengalaman usahatani petani rata-rata yaitu 10-20 tahun dengan jumlah 29 orang atau 41,4\%, menurut Soekartawi (2002) petani yang sudah lama berusahatani akan lebih mudah menerapkan te knologi daripada petani pemula. Tingkat kekosmopolitan merupakan tingkat intensitas petani mencari informasi diluar tempat tinggalnya. Berdasarkan tabel di atas dapat dilihat bahwa intensitas petani mencari informasi diluar tempat tinggalnya masih rendah dengan jumlah satu kali sebanyak 27 responden atau $38,6 \%$. 
Tabel 2. Karakteristik Petani yang Dipengaruhi dari dalam Dirinya Sendiri

\begin{tabular}{|c|c|c|c|c|}
\hline No & Karakteristik Petani & Tingkatkan & Jumlah (Orang) & Presentase (\%) \\
\hline \multirow{5}{*}{1} & \multirow{5}{*}{ Umur } & $24-33$ & 7 & 10 \\
\hline & & $34-42$ & 21 & 30 \\
\hline & & $43-51$ & 26 & 37,1 \\
\hline & & $52-60$ & 11 & 15,7 \\
\hline & & $61-68$ & 5 & 7,1 \\
\hline & Total & & 70 & 100 \\
\hline \multirow{4}{*}{2} & \multirow{3}{*}{ Pendidikan } & SD & 17 & 24,3 \\
\hline & & SMP & 22 & 31,4 \\
\hline & & SMA & 31 & 44,3 \\
\hline & Total & & 70 & 100 \\
\hline \multirow{6}{*}{3} & \multirow{5}{*}{ Luas Lahan } & $<0,1$ & 2 & 2,9 \\
\hline & & $0,2-0,4$ & 26 & 37,1 \\
\hline & & $0,5-0,7$ & 25 & 35,7 \\
\hline & & $0,8-1$ & 4 & 5,7 \\
\hline & & $>1$ & 13 & 18,6 \\
\hline & Total & & 70 & 100 \\
\hline
\end{tabular}

\section{Deskripsi Kohesivitas Kelompoktani di Desa Karangrejo}

Kohesivitas merupakan salah satu hal yang penting bagi kelompok karena kohesi vitas merupakan alat pemersatu anggota agar dapat menjadi sebuah kelompok yang efektik. Tingkat kohesivitas berdasarkan indikatornya pada anggota kelompoktani di Desa Karangrejo, Kecamatan Kendal, Kabupaten Ngawi disajikan pada Tabel 4.

Berdasarkan Tabel 4 diketahui bahwa loyalitas kelompoktani tergolong tinggi dengan presentase $90 \%$, hal ini berarti anggota loyal terhadap kelompoknya. Loyalitas merupakan sebuah tekad dan kesan ggupan menaati, melaksanakan, dan mengamalkan sesuatu yang ditaati dengan penuh kesadaran dan tanggung jawab. Bentuk loyalitas anggota terhadap kelompoknya, dilihat dari seberapa besar keterlibatan anggota dalam melakukan kegiatan kelompok salah satunya yaitu anggota dengan rela menyumbangkan sesuatu yang berupa gagasan, ide atau materi sehingga tujuan kelompok tersebut dapat tercapai. Solidaritas kelompok tani dalam program penggunaan Varietas Unggul Baru komoditas padi tinggi dengan presentase $71.43 \%$ hal ini dapat dilihat dari kerjasama yang dilakukan antar anggota dalam pelaksanaan program, solidaritas merupakan rasa kebersamaan, rasa kesatuan, kepentingan, rasa simpati, sebagai salah satu anggota kelompok atau dapat diartikan sebagi ungkapan dalam sebuah kelompok yang dibentuk oleh kepentingan bersama.

Daya tarik anggota kelompok tani terhadap program penggunaan Varietas unggul Baru komoditas padi tinggi $75.71 \%$, daya tarik merupakan sebuah keinginan atau ketertarikan akan sesuatu hal yang menjadikan mereka ingin tetap tinggal dalam kelompoknya. Kerjasama kelompoktani dalam melaksankan program penggunaan Varietas Unggul Baru Komoditas Padi rendah dengan presentase $54.29 \%$, Kerjasama merupakan kepedulian satu orang atau satu pihak dengan orang atau pihak lain yang tercermin dalam suatu kegiatan yang menguntungkan semua pihak. Berdasarkan uraian di atas maka dapat disimpulkan bahwa kohesivitas kelompoktani Ngudi Rahayu dan Sedyo Mulyo tergolong tinggi. 
Tabel 3. Karakteristik Petani yang Dipengaruhi oleh Lingkungan

\begin{tabular}{|c|c|c|c|c|}
\hline No & Karakteristik Petani & Tingkatan & Jumlah (orang) & Presentase (\%) \\
\hline \multirow{6}{*}{1} & \multirow{5}{*}{ Lama Berusahatani } & $1-10$ & 11 & 15,7 \\
\hline & & $11-20$ & 29 & 41,4 \\
\hline & & $21-30$ & 16 & 22,9 \\
\hline & & $31-40$ & 12 & 17,1 \\
\hline & & $41-50$ & 2 & 2,9 \\
\hline & Total & & 70 & 100 \\
\hline \multirow{6}{*}{6} & \multirow{5}{*}{ Kekosmopolitan } & Tidak Pernah & 27 & 38,6 \\
\hline & & 1 kali & 31 & 44,3 \\
\hline & & 2 kali & 7 & 10,0 \\
\hline & & 3 kali & 4 & 5,7 \\
\hline & & $>4$ kali & 1 & 1,4 \\
\hline & Total & & 70 & 100 \\
\hline \multirow{6}{*}{3} & \multirow{5}{*}{ Pelatihan } & Tidak pernah & 9 & 12,9 \\
\hline & & 1-2 kali & 23 & 32,9 \\
\hline & & 3-4 kali & 24 & 34,3 \\
\hline & & $5-6$ kali & 12 & 17,1 \\
\hline & & $>7$ kali & 2 & 2,9 \\
\hline & Total & & 70 & 100 \\
\hline
\end{tabular}

Analisis Hubungan Karakteristik Petani dan Kohesivitas Kelompoktani

Analisis Korelasi digunakan untuk mengetahui derajat atau kekuatan hubungan antara dua variabel atau lebih. Penggunaan analisis korelasi juga untuk mengetahui kontribusi yang diberikan oleh variabel $\mathrm{X}_{1}$ (Umur), $\quad \mathrm{X}_{2}$ (Tingkat Pendidikan), $\mathrm{X}_{3}$ (Pelatihan), $\mathrm{X}_{4}$ (Pengalaman Usahatani), $\mathrm{X}_{5}$ (Luas Lahan), $\mathrm{X}_{6}$ (Kohesivitas), $\mathrm{X}_{7}$ (Peran Pen yuluh), $\mathrm{X}_{8}$ (Pemanfaatan Media) terhadap variabel $Y$ (kohesivitas anggota kelompoktani). Hasil analisis korelasi disajikan Tabel 5.

Berdasarkan Tabel 5 dapat diketahui bahwa pendidikan memiliki hubungan yang lemah dengan nilai koefisien korelasi sebesar 0,417 , bernilai positif yang berarti memiliki hubungan yang searah dan nilai signifikansinya sebesar 0,00 yang berarti memiliki hubungan yang signifikan. Menurut Chavas et al. (2005) petani dengan kategori pendidikan lebih tinggi cenderung lebih mudah menerima inovasi-inovasi baru. Salah

Tabel 4. Tingkat Kohesivitas Kelompoktani Ngudi Rahayu dan Sedyo Mulyo

\begin{tabular}{ccccc}
\hline Tingkat & Kategori & Interval Nilai Hasil & Jumlah Responden & Presentase\% \\
\hline \multirow{2}{*}{ Loyalitas } & Tinggi & $14,6-20$ & 63 & 90 \\
& Rendah & $9-14,5$ & 7 & 10 \\
\multirow{2}{*}{ Solidaritas } & Tinggi & $19,6-25$ & 50 & 71.43 \\
& Rendah & $14-19,5$ & 20 & 28.57 \\
\multirow{2}{*}{ Daya tarik } & Tinggi & $5-10$ & 53 & 75.71 \\
\cline { 1 - 2 } Kerjasama & Rendah & $11-15$ & 17 & 24.29 \\
& Tinggi & $5-10$ & 32 & 45.71 \\
& Rendah & $11-15$ & 38 & 54.29 \\
\hline
\end{tabular}


Tabel 5. Analisis Korelasi Faktor Internal terhadap Kohesivitas Kelompoktani

\begin{tabular}{|c|c|c|c|c|c|c|}
\hline No & Variabel & $\begin{array}{c}\text { Arah } \\
\text { Hubungan }\end{array}$ & $\begin{array}{c}\text { Kekuatan } \\
\text { Hubungan }\end{array}$ & Kriteria & Signifikasi & Kriteria \\
\hline 1 & Umur & Searah & 0,135 & $\begin{array}{l}\text { Sangat } \\
\text { Lemah }\end{array}$ & 0,266 & $\begin{array}{l}\text { Tidak } \\
\text { Signifikan }\end{array}$ \\
\hline 2 & Pendidikan & Searah & 0,417 & Lemah & 0,000 & Signifikan \\
\hline 3 & Pelatihan & $\begin{array}{l}\text { Tidak } \\
\text { Searah }\end{array}$ & $-0,037$ & $\begin{array}{l}\text { Sangat } \\
\text { Lemah }\end{array}$ & 0,764 & $\begin{array}{l}\text { Tidak } \\
\text { Signifikan }\end{array}$ \\
\hline 4 & $\begin{array}{l}\text { Lama } \\
\text { Berusahatani }\end{array}$ & $\begin{array}{l}\text { Tidak } \\
\text { Searah }\end{array}$ & $-0,222$ & $\begin{array}{l}\text { Sangat } \\
\text { Lemah }\end{array}$ & 0,065 & $\begin{array}{l}\text { Tidak } \\
\text { Signifikan }\end{array}$ \\
\hline 5 & Luas Lahan & Searah & 0,089 & $\begin{array}{l}\text { Sangat } \\
\text { Lemah }\end{array}$ & 0,465 & $\begin{array}{l}\text { Tidak } \\
\text { Signifikan }\end{array}$ \\
\hline 6 & Kekosmopolitan & $\begin{array}{l}\text { Tidak } \\
\text { Searah }\end{array}$ & $-0,058$ & $\begin{array}{l}\text { Sangat } \\
\text { Lemah }\end{array}$ & 0,635 & $\begin{array}{l}\text { Tidak } \\
\text { Signifikan }\end{array}$ \\
\hline
\end{tabular}

satu inovasi yang diterima petani yaitu program penggunaan Varietas Unggul Baru komoditas padi. Petani dengan pendidikan tinggi akan lebih sadar fungsi dari kelompok tani yang sebenarnya.

Umur petani memiliki hubungan positif dengan kohesivitas kelompok, hal ini dapat dilihat dari nilai koefisien korelasinya sebesar 0,135 , dan nilai signifikasinya sebesar 0,266 yang berarti memiliki hubungan yang tidak signifikan. Pelatihan memiliki hubungan negatif ditunjukan dari nilai koefisien korelasinya yaitu sebesar $(-0,037)$ dan memiliki hubungan yang tidak signifikan dengan nilai signifikansi sebesar 0,764 dimana nilai tersebut lebih besar dari 0,05. Pelatihan dalam bidang usahatani padi yang dilakukan oleh petani masih relatif rendah yaitu rata-rata 3-4 kali. Pelatihan sangat diperlukan guna meningkatkan keterampilan petani. Semakin sering pelatihan dilakukan maka akan meningkatkan daya tarik anggota kelompok agar tetap berada dalam kelompok tersebut.

Lama berusaha tani memiliki hubungan yang sangat lemah dan tidak searah hal ini berdasarkan nilai koefisien korelasi sebesar (0,222 ) dan memiliki hubungan yang tidak signifikan karena nilai signifikansinya sebesar 0,065. Menurut Pratiwi dan Sudrajat (2012) lama bertani akan berpengaruh nyata terhadap perilaku petani dalam mengelola lahan pertaniannya, semakin lama bertani maka tingkat pengalaman yang dimiliki akan semakin tinggi, dan akan memiliki perilaku dalam mengelola lahan. Tingkat kohesivitas pada anggota kelompok tani tidak terlalu berkaitan dengan lamanya menjadi petani, menurut Myers (2012) adalah perasaan "we feeling" yang mempersatukan setiap anggota kelompok menjadi satu bagian.

Luas lahan memiliki hubungan yang sangat lemah dan searah dengan nilai koefisien korelasi sebesar 0,096 sedangkan untuk nilai signifikasninya sebesar 0,427 yang berarti tidak signifikan. Hal ini berarti luas lahan tidak terlalu berkaitan dengan kohesivitas kelompok tani. Menurut Iriana et al. (2017) luas lahan menentukan pendapatan, taraf hidup petani, luas lahan juga akan berpengaruh terhadap adopsi inovasi. Dalam penelitian ini luas lahan yang dimiliki petani tergolong sempit karena rata-rata 0,2-0,4 ha.

Tingkat Kekosmopolitan memiliki hubungan yang sangat lemah dan tidak searah karena memiliki nilai koefisien korelasi sebesar $(-0,58)$ dan memiliki nilai signifikansi 0,635 yang berarti tidak signifikan. Tingkat kosmopolitan responden penelitian masih tergolong rendah karena intensitas petani 
Tabel 6. Analisis Korelasi Faktor Eksternal terhadap Kohesivitas Kelompoktani

\begin{tabular}{lllllll}
\hline No & \multicolumn{1}{c}{ Variabel } & $\begin{array}{c}\text { Arah } \\
\text { Hubungan }\end{array}$ & $\begin{array}{c}\text { Kekuatan } \\
\text { Hubungan }\end{array}$ & Kriteria & Signifikasi & Kriteria \\
\hline 1 & $\begin{array}{l}\text { Interaksi dengan } \\
\text { Penyuluh }\end{array}$ & Searah & 0,606 & Kuat & 0,00 & Signifikan \\
2 & $\begin{array}{l}\text { Pemanfaatan } \\
\text { Media }\end{array}$ & Searah & 0,302 & Lemah & 0,011 & Signifikan \\
\hline
\end{tabular}

mencari informasi diluar daerahnya rendah yaitu rata-rata dilakukan satu kali. Hal ini berarti tingkat kekosmopolitan tidak terlalu berkaitan dengan kohesivitas kelompok.

Dapat disimpukan bahwa faktor internal yang memiliki hubungan kuat dan signifikan yaitu pendidikan sedangkan hubungan yang lemah dan tidak signifikan yaitu umur, pelatiham, lama berusahatani, luas lahan, dan tingkat kekosmopolitan.

Berdasarkan Tabel 6 di atas dapat diketahui bahwa interaksi dengan penyuluh dan pemanfaatan media memiliki hubungan yang kuat signifikan dan cukup signifikan. Interaksi dengan penyuluh memiliki hubungan positif karena nilai koefisien korelasi sebesar 0,606 dan nilai signifikansi sebesar 0,00 yang berarti signifikan. Artinya semakin intensif penyuluh melakukan interaksi dengan petani dalam kegiatan kelompok maka kohesivitas kelompok tani akan semakin meningkat. Menurut Mardikanto (2009) kegiatan penyuluhan sangat diperlukan untuk memperlancar pembangunan dalam bidang pertanian. Interaksi dengan penyuluh memiliki hubungan yang kuat karena penyuluh bertugas untuk menyampaikan informasi tentang inovasi-inovasi dalam bidang pertanian. Semakin intensif interaksi yang dilakukan penyuluh dengan petani melalui pertemuan kelompok diharapkan dapat memecahkan permasalahan yang dihadapi petani sehingga petani merasa adanya kelompok tani memberikan manfaat bagi dirinya dan petani tertarik untuk tetap berada dalam kelompok tersebut.

Pemanfaatan media memiliki kekuatan hubungan yang positif karena nilai koefisien korelasi sebesar 0,302 sedangkan nilai signifikasi bernilai 0,011 yang berarti signifikan. Media komunikasi sangat penting dalam proses berkomunikasi antara petani dengan penyuluh. Dengan komunikasi yang baik maka petani dapat dengan mudah menerima informasi-informasi yang disampaikan penyuluh dalam kegiatan kelompok. Hal ini berpengaruh terhadaap ketertarikan petani untuk tetap berada dalam kelompoknya.

\section{SIMPULAN DAN SARAN}

1. Karakteristik petani yang ada di Desa Karangrejo Kecamatan Kendal Kabupaten Ngawi yaitu rata-rata umur petani 43 sampai 51 tahun, tingkat pendidikan petani yaitu rata-rata SMA, pelatihan dilakukan sebanyak 3-4, usahatani yang telah dilakukan responden yaitu rata-rata 11-20 tahun, luas lahan yang dimiliki responden yaitu sekitar 0,2-0,4 ha, tingkat kekosmopolitan responden yaitu rata-rata satu kali.

2. Kohesivitas anggota kelompoktani di Desa Karangrejo Kecamatan Kendal Kabupaten Ngawi dalam penggunaan Varietas Unggul Baru (VUB) komoditas padi pada indikator loyalitas tinggi yaitu sebesar 90\%, solidaritas tinggi yaitu sebesar 71,43\%, daya tarik tinggi yaitu sebesar $75,71 \%$, dan kerjasama rendah yaitu sebesar 54,29\%.

3. Hubungan yang terbentuk dari delapan karakteristik petani terhadap kohesivitas anggota kelompoktani yaitu terdapat tiga karakteristik yang memiliki hubungan signifikan dengan kohesivitas yaitu pendidikan, interaksi dengan penyuluh, dan pemafaatan media. Sedangkan 
karakteristik yang tidak memiliki hubungan signifikan yaitu umur, pelatihan, lama berusahatani, luas lahan, dan kekosmopolitan.

\section{DAFTAR PUSTAKA}

Chavas, J. P., R. Petrie, dan M. Roth. 2005. Farm Household production efficiency: Evidence from the Gambia. American journal of Agricultural Economics 87(1): 160-179. https://doi.org/10.1111/j.00029092.2005.00709.x

Iriana, B., E. Novianti, C. C. Priyatna, dan H. R. Budiana. 2017. Hubungan antara karakteristik individu petani dengan kohesivitas kelompok tani tanaman obat. Profesi Humas: Jurnal Ilmiah Ilmu Hubungan Masyarakat 1(2): 153-163.

Mardikanto, T. 2009. Sistem Penyuluhan Pertanian. Surakarta: Sebelas Maret University Press.

Mislini. 2006. Analisis jaringan komunikasi pada kelompok swadaya masyarakat: kasus ksm di Desa Tamansari, Kabupaten Bogor, Provinsi Jawa Barat. Tesis. Bogor: Sekolah Pascasarajan IPB.

Myers, D. G. 2012. Psikologi sosial jilid 2. Jakarta: Salemba Humanika.

Pratiwi, E. R. dan Sudrajat. 2012. Perilaku petani dalam mengelola lahan pertanian di kawasan rawan bencana longsor (studi kasus desa sumberejo, kecamatan batur, kabupaten banjarnegara-jateng). Jurnal Bumi Indonesia 1(3): 356-362.

Robbins, S. P. dan T. J. Judge. 2002. Organization Behavior. Alih Bahasa Dr Handayani Pujoatmoko. Jakarta: PT Prenhaltindo.

Soekartawi. 2002. Analisis Usaha Tani. Jakarta: UI - Press.

Walgito, B. 2007. Psikologi Kelompok. Yogyakarta: Andi Offset.

Yuniasanti, R. 2010. Pelatihan pembentukan tim untuk meningkatkan kohesivitas tim pada tim devisi produksi. Insight $8(1)$ : 71-72. 